\title{
Cuerpos y desplazamientos. Retos feministas en un marco pos/decolonial ${ }^{1}$
}

\section{Larisa Pérez Flores ${ }^{2}$}

Recepción: 30 de abril de 2014 / Aprobación: 25 de junio de 2014

\section{Resumen}

El objetivo de este artículo es dibujar un mapa de los retos feministas actuales. Para ello será necesario definir tanto dicha "actualidad" como el propio feminismo. Lo primero se traducirá en describir el contexto social y teórico mundial en relación con el colonialismo, siguiendo el eco de las teorías poscoloniales y decoloniales. Lo segundo consistirá en sintetizar la problematización de la noción de feminismo llevada a cabo desde los márgenes del propio movimiento en las últimas décadas. Un tercer paso consistirá en relacionar el marco social y teórico poscolonial con dicha redefinición del feminismo, para lo que haremos uso del concepto de "diáspora". Este último, que será brevemente problematizado, se propondrá como ineludible para entender el giro de tuerca en la reciente teoría social. Para ello se mostrará la relación de la diáspora, como fenómeno social, con los orígenes históricos de los nuevos feminismos y las teorías pos/decoloniales.

\section{Palabras clave}

Feminismo; poscolonial; decolonial; diáspora; interseccional

\section{Abstract}

The aim of this article is to map the current challenges of feminism. Thus, it is necessary to define both "the Present" and feminism itself. Firstly, the social and theoretical global context in relation to colonialism, echoing postcolonial and decolonial theories, is described. Secondly, the problematisation of the notion of feminism conducted by the movement itself in recent decades is synthesized. And, finally, the social and theoretical postcolonial framework is intertwined with the redefinition of feminism, for which the term "diaspora" is used. This term, which is briefly problematised, is also proposed as essential to understand the twist on social theory during the last decades.

$1 \quad$ Este artículo es el desarrollo de algunos de los aspectos abordados en mi reciente publicación: Jamaica Kincaid y la diáspora antillana: mujeres, islas y jaulas (Pérez, 2014). Se utilizarán los hallazgos de este estudio de caso para llevar a cabo una reflexión general acerca de los retos actuales del feminismo en un marco pos/decolonial.

2 Española. Licenciada en Filosofía por la Universidad de La Laguna (ULL), España. Máster en Estudios Norteamericanos por la Universidad de Pisa. Doctoranda de la ULL en el programa de Formación del Profesorado Universitario del Ministerio de Ciencia e Innovación de España. Correo electrónico: larisa_mol@hotmail.com 
To do so, it is exposed how the "diaspora" as a social phenomenon associates with the historical origins of new feminism and post / decolonial theory.

\section{Keywords}

Postcolonial; decolonial; feminism; diaspora; intersectional

\section{Resumo}

O objetivo deste artigo é o de desenhar um mapa dos desafios feministas atuais. Isso exigirá que se defina primeiramente tanto o "tempo atual" como o próprio feminismo. A primeira definição consistirá em descrever o contexto social e teórico global em relação ao colonialismo, seguindo o eco das teorias pós-coloniais e decoloniais. A segunda definição incidirá em sintetizar a problematização da noção de feminismo realizada a partir das margens do próprio movimento nas ultimas décadas. Um terceiro passo será relacionar o quadro social e teórico pós-colonial com a citada redefinição de feminismo, para o qual usaremos o termo "diáspora". Este ultimo, que será problematizado de uma forma breve, será proposto como indispensável para entender a reviravolta na teoria social das ultimas décadas. Para isso, será mostrada a relação da diáspora como um fenômeno social, com as origens históricas dos novos feminismos e as teorias pós/decoloniais.

\section{Palavras chave}

Feminismo; poscolonial; decolonial; diáspora; interseccional

\section{Poscolonialismo y decolonialismo}

Eia pour ceux qui n'ont jamais rien inventé pour ceux qui n'ont jamais rien exploré pour ceux qui n'ont jamais rien dompté

Aimé Césaire

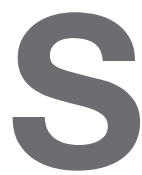

e podrían elegir diferentes estrategias para definir algo tan difuso como el panorama mundial. Aquí optaremos por seguir la herencia del pensamiento pos/decolonial, porque entendemos que toda teoría social que prescinda del cuestionamiento radical que este pensamiento implica será insuficiente. Lo elegimos, no porque nos dote de todos los instrumentos de análisis necesarios, sino porque nos provee de ciertos instrumentos ineludibles. Vivimos en una época en la que, como dijera Hofmannsthal en su Carta a Lord Chandos (1990), las grandes palabras se nos deshacen en la boca como hongos podridos. La filosofía, el arte e incluso la ciencia viven una fase de cuestionamiento de sus propios métodos y principios epistemológicos. En esta fase se ha puesto a la modernidad en el ojo de mira, tanto que es usual englobarla bajo el término "posmodernidad". Pero, 
¿qué es la modernidad? Como relato, se la suele representar como una redefinición de lo humano en torno a la Razón. Como fenómeno sociohistórico de origen europeo, se la puede caracterizar a partir de una serie de episodios económicos y culturales relacionados entre sí de forma compleja, como el capitalismo, el patriarcado o el colonialismo.

Las teorías poscoloniales parten de este último punto, a saber, de la cuestión colonial, para empezar a teorizar. La novedad de estos planteamientos frente a otros cuestionamientos de la modernidad dentro de la tradición filosófica occidental reside precisamente en el lugar de emisión del discurso. Por primera vez, el lugar de emisión es periférico. Son voces de las colonias o excolonias quienes cuestionan el paradigma socioeconómico y cultural vigente. $Y$ lo hacen desde un pensamiento fuera, o al menos en la frontera, del perímetro del griego y del latín, de las seis lenguas imperiales modernas, de la racionalidad europea (Mignolo, 2007, p. 27).

Las producciones teóricas y artísticas poscoloniales nacen en la búsqueda de un discurso propio. Derek Walcott, escritor nacido en Santa Lucía, expresó esta tarea así: "We were blest with a virginal, unpainted world / with Adam's task of giving things their names [Fuimos bendecidos/as con un mundo sin pintar, virgen / con la tarea adánica de darles a las cosas sus nombres]"(citado por James, 1999, p. 101). Esta tarea adánica de nombrar por primera vez es el único modo, según Walter Benjamin (1991), de dar con la verdad. Pero no se trata de dar con algún tipo de Verdad con mayúsculas, sino de avanzar a partir del hallazgo posmoderno-poscolonial más fundamental: la verdad no es "transhistórica" ni "transoceánica" El poeta Kamau Brathwaite, nacido en Barbados, lo expresó así: "the hurricane does not roar in pentameters [el huracán no ruge en pentámetros]" (citado por Innes, 2007, p. 107). El pentámetro de la poesía inglesa expresa un espacio y tiempo concretos, un espacio y un tiempo que no tienen que ver con la condición ciclónica, por ejemplo, del Caribe. Quizá sirva para definir la caída de las hojas en otoño, pero no el huracán.

Estos autores antillanos, como tantos otros, se propusieron quitarle el blanco polvo a sus tesoros negros. Recogieron el habla criolla, los cuentos de la abuela, los rezos prohibidos, el sonido de las alimañas en la noche caliente. Vienen de un área paradigmática, de unas islas que son las musas indiscutibles de lo colonial. De ahí probablemente sus magníficas contribuciones. Por eso propongo tomarlas como punto de partida. Porque el tráfico de cuerpos

$3 \quad$ Utilizo el término "post-moderno", a pesar de la amplia discusión en torno al mismo, en igual sentido en el que uso el término "post-colonial". En ningún caso implica señalar el fin de la condición moderna o colonial del presente, sino un cuestionamento de estos sistemas de conocimiento y práctica. Coincido además con la crítica de Enrique Dussel (2005) referente a la imposibilidad de conjugar posmodernismo y poscolonialismo, dado que lo "posmoderno" es un fenómeno europeoestadounidense. El poscolonialismo tiene que responder críticamente tanto a la Modernidad como a la Posmodernidad como fenómenos eurocéntricos. 
que ha pasado y sigue pasando por esas islas persiguiendo mitos, traficando con otros cuerpos para conseguirlos, ha sido tan grande que nos ha dejado el mayor cementerio oceánico de la Historia. Un cementerio sin lápidas.

Partimos del hecho de que la mayoría de los cuerpos que se instalaron en las Antillas tras el genocidio aborigen fueron "importaciones" habilitadas por el mayor exilio forzoso de la historia. No había solo cuerpos africanos en esta migración, sino europeos y asiáticos, unidos por el hecho fundamental de poseer pocas cosas. Entre estas pocas cosas por supuesto no se encontraban las armas para defenderse de quienes poseían muchas cosas, incluidos los cuerpos de otras personas. El colonialismo, como expresión del desarrollo capitalista, necesitaba mano de obra para nuevas áreas de explotación, y la esclavitud explícita sería utilizada hasta que fuera preferible el trabajo asalariado (debido a las revoluciones europeas, la devaluación del azúcar de caña frente a la de remolacha y otros elementos de la historia del mundo capitalista). Entonces, cuando los viejos imperios empezaron a necesitar más mano de obra, el flujo migratorio invirtió su dirección y nacieron las modernas diásporas hacia Europa y los nuevos imperios, como Estados Unidos de América.

Este análisis de caso, en tanto análisis básico poscolonial, muestra algo fundamental: cómo los desplazamientos de los cuerpos y de las cosas están regulados políticamente. Una persona estadounidense llega a la pequeña isla de Antigua con la misma facilidad con la que llega un producto de una empresa estadounidense. Sin embargo, una persona migrante de Antigua accede a los Estados Unidos con la misma dificultad que un producto de una empresa de Antigua. La persona estadounidense adquirirá un estatus social en Antigua inversamente proporcional al estatus que adquirirá una migrante antillana en Estados Unidos. Esto quiere decir que las relaciones de poder regulan los movimientos, pero no solo los migratorios sino los movimientos en el espacio urbano, doméstico, o los propios movimientos corporales. Como se mostrará más adelante, son los dispositivos de control del movimiento de los cuerpos los que definen la identidad.

Para analizarlos precisamos de un aparato teórico complejo y transdisciplinar. ¿Es el caso del poscolonialismo? Desde luego, el colonialismo puede parecer un fenómeno ineludible, pero insuficiente, en la descripción de estos desplazamientos. Una posibilidad es acudir a la ampliación conceptual de "lo colonial" que propone el sociólogo peruano Aníbal Quijano al hablar de la "colonialidad de poder". Esta expresión, fundamental para la diversidad de autoras y autores latinoamericanos que transitan el llamado proyecto "Modernidad/Colonialidad", pretende señalar la permanencia del pensamiento y las prácticas coloniales en los cuerpos, independientemente de los procesos de independencia 4 . Ya que el término "poscolonial" puede resultar confuso a este respecto, pues el neocolonialismo define el panorama actual, se prefiere

$4 \quad$ Para una buena antología/síntesis del proyecto ver Castro Gómez y Grosfoguel (2007). 
la idea de "pensamiento decolonial", como oposición explícita a la herencia socioeconómica y cultural de la modernidad.

Lo interesante de la idea de "decolonialidad" es que nada, desde la economía hasta la discriminación racial, está desconectado. Frente a la fragmentación del conocimiento que caracteriza al panorama de la ciencia social, Quijano sugiere que:

El capitalismo no es sólo un sistema económico (paradigma de la economía política) y tampoco es sólo un sistema cultural (paradigma de los estudios culturales/poscoloniales en su vertiente 'anglo'), sino que es una red global de poder, integrada por procesos económicos, políticos y culturales, cuya suma mantiene todo el sistema (2007, p. 17).

De este modo, la "colonialidad del poder" nos habla de un proceso heterogéneo donde se integran las múltiples jerarquías de poder del capitalismo. El reto es entender cómo estas jerarquías se relacionan para configurar la identidad.

\section{Identidades diaspóricas I}

Je ne suis jamais arrivé à comprendre comment on parvient a vivre dans une autre culture que la sienne. Malgré ces trente-trois ans passés a Montreal le mystère reste pour moi complet. Comme s'il s'agissait de quelqu'un d'autre.

Dany Laferrière

La migración, más o menos forzada, es una característica fundamental del imperialismo, en el sentido de que este ha precisado del colonialismo y, el colonialismo, a su vez, ha precisado, históricamente, de un desplazamiento notable de cuerpos. Si no tenemos esto en cuenta, nos perderemos la mitad de la historia, navegaremos en el crucero sin darnos cuenta de los muertos que descansan bajo el agua. Pero sigamos con el caso caribeño. Jamaica Kincaid, autora antiguana, es un cuerpo de corazón diaspórico que dejó las Antillas para alcanzar una nueva vida en los Estados Unidos. Lo hizo en un contexto caracterizado por una serie de fenómenos relacionados entre sí: las migraciones masivas tras la Segunda Guerra Mundial, el auge del "American" Dream5, la explosión demográfica en las Antillas y el apogeo de las dictaduras caribeñas y latinoamericanas (auspiciadas y/o perpetradas, casi sin excepción, por Estados Unidos). Y lo cierto es que conocemos a Kincaid porque emigró al imperio. De lo contrario sería una nadie, como dice Eduardo Galeano (2005), y ni siquiera se hubiera llamado a sí misma Jamaica. Es escritora porque emigró. Su estilo, así como los contenidos de su trabajo, son inseparables de su desplazamiento.

Lo interesante de este ejemplo es que Kincaid, como el resto de voces migrantes antillanas que hemos citado, quiere forjar su destino lejos de su hogar, lejos del pequeño lugar de donde viene. Este lugar es la fuente de su devoción

5 Entrecomillo "American" porque nunca se trató de un sueño americano, ni siquiera norteamericano, sino estadounidense. 
al tiempo que el motor de su vuelo. ¿Se trata de una migración forzada? Tomemos un fragmento de su obra fundamental, La autobiografía de mi madre:

Su padre era un hombre escocés, su madre pertenecía al pueblo africano, y esta distinción entre hombre y pueblo era una distinción importante, pues uno de ellos desembarcó siendo parte de una horda, ya condenada, la mente vacía de todo lo que no fuera sufrimiento humano, cada rostro idéntico al que tenía a su lado; el otro desembarcó por voluntad propia, ambicionando realizar un destino, llevando en la imaginación la vida de sí mismo con la que soñaba (Kincaid, 2007, p. 147).

¿Es Jamaica Kincaid y el resto de voces caribeñas emigradas a Norteamérica, el padre o la madre? Sus ancestros son los perdedores, pero ambicionan un destino. Sus cuerpos están marcados por un desplazamiento histórico dramático, pero también por desplazamientos recientes, por migraciones en busca de un "mejor futuro", eso que Aimé Cesaire llama un encubierto "genocidio por sustitución"6.

Forma parte de una diáspora, aunque varíen los motivos y el lugar y el modo en los que llevó a cabo su migración con respecto del resto de miembros. Pero este término, "diáspora", cuyo éxito en los últimos tiempos ha difuminado los límites de su significado, no deja de ser problemático para el caso antillano. Generalmente, cuando se utiliza se alude a la antigüedad del grupo emigrado, esto es a la existencia de varias generaciones conviviendo en el lugar de emigración, y a la persistencia de una identidad compartida del grupo en modo alguno fusionable con la identidad "nacional" del lugar de asentamiento. Para reproducir esta identidad, se presupone un capital iconográfico que conecta el lugar de la "memoria" (sea real o imaginario) con el del presente (Bruneau, 2010). Pero claro, cuando hablamos de diáspora antillana, por ejemplo, ¿cuál es la identidad compartida resultado de dicho recorrido, cuál es la identidad que relaciona dicho capital? Este es uno de los problemas de la identidad en un marco diaspórico/poscolonial.

De modo que, últimamente, se aplica el término "trasnacional" para referir a comunidades provenientes de las excolonias cuya migración está integrada en las dinámicas propias del neocolonialismo. Estas dinámicas serían, en palabras de A. Portes: "primero, las necesidades de mano de obra de las economías del Primer Mundo, en particular la necesidad de nuevos suministros de mano de obra barata. Segundo, la penetración en los países periféricos de la inversión productiva, las normas de consumo, y la cultura popular de las sociedades avanzadas"7 (1997, p. 5). Una migración donde no hay exilio político o religioso común, donde no se añora un estado real o imaginario, donde no se

6 Cesaire se refiere a la migración indirectamente forzosa como método para limpiar étnica y culturalmente una región, procurando sustituir a la población por colonos metropolitanos. Para una explicación más detallada del concepto, ver la descripción de Glissant (1981, p. 498) 
trata de una misión común empresarial como en el caso de China o India. ¿No sería acaso preferible tal término para el caso antillano?

Respondiendo a las dos preguntas, aquí se habla de "diáspora" básicamente porque se quiere dar cuenta de la complejidad de las migraciones en el espacio al que referimos, con presencia de exilios, tierras soñadas, flujos económicos neocoloniales, pasado esclavista, discurso poscolonial, etcétera. Ello no entraría en contradicción con la idea de que actualmente existe una comunidad antillana trasnacional. Persiste no obstante la dificultad de delimitar una identidad en diáspora cuando no se puede evocar una nación común de procedencia. Para el caso de las Antillas, el concepto de black diaspora sirvió en buena medida para paliar tal dificultad y, seguramente, buena parte de la migración antillana se sentiría identificada con esa memoria y la iconografía que la acompaña, donde África es la "nación de procedencia" y para algunas personas, incluso, la "tierra prometida". Pero claro, lo antillano no es lo negro. Este concepto, nacido en el contexto estadounidense, no basta y la distinción entre sujetos afrocaribeños y afroamericanos no se difumina fácilmente ${ }^{8}$.

Por esto, muchos han referido a lo antillano como lo criollo. El escritor y filósofo martiniqués, Édouard Glissant, habla de criollización como procesoresultado de "una mezcla no reducible a sus componentes individuales, como un proceso imparable y rico que, en vez de enfocarse desde la óptica del dolor, se enfoque desde una óptica constructiva"9 (1981, p. 497). Nicolás Guillén, escritor cubano, mulato descendiente de mulatos, habla del mestizaje y recupera un sentimiento de panantillanidad similar al de Glissant. Esto es un fragmento de su Son para niños antillanos, de 1947 (2003):

Por el Mar de las Antillas anda un barco de papel: Anda y anda el barco barco, sin timonel.

De La Habana a Portobelo, de Jamaica a Trinidad, anda y anda el barco barco sin capitán.

Una negra va en la popa, va en la proa un español: Anda y anda el barco barco, con ellos dos.

Pasan islas, islas, islas, muchas islas, siempre más; anda y anda el barco barco, sin descansar.

8 Ver confrontación en la novela de Tony Morrison Tony: La isla de los caballeros (1993).

9 Traducción propia. 
Un cañón de chocolate

contra el barco disparó, y un cañón de azúcar, azúcar, le contestó.

¡Ay, mi barco marinero, con su casco de papel!

¡Ay, mi barco negro y blanco sin timonel!

El mensaje es claramente integrador. El español va en la proa, dirigiendo el rumbo, y la negra va detrás, pero van juntos los dos dejando una descendencia mulata a un mundo de islas, cacao y caña. Eso son las Antillas: Europa, África y plantación. Aquí se habla de una raza unida, como dijera Bolívar; de una identidad de cruce. Se reivindica un mundo mulato. Y sí, mulato viene de mula, híbrido de burro y yegua. Lo híbrido es un cruce antinatural, una mezcla prohibida que es castigada con esterilidad. Pero la raza criolla es raza fecunda, y la hibridicidad es pues un don. Aquí se reivindica el insulto; los perdedores y las perdedoras exhiben con orgullo la historia de su tierra y de su cuerpo, writing back to the empire.

Pero hay dos problemas. Primero, este sentimiento "teórico" brilla por su ausencia en el pecho de los cuerpos antillanos, pues la impronta lingüísticocolonial ha dejado muchas fronteras invisibles. En las islas inglesas muchas personas se denominan "caribbean" y en las francesas "antillais" y en las españolas "latinas", y para entender cada cosa habría que contar una larga historia que ahora no podemos contar. Segundo, esa tierra y esos cuerpos de corazón diaspórico son tan variados, en ellos intersectan tantas opresiones, que no es fácil saber desde qué identidad erigir el discurso. ¿Racial? ¿Nacional? ¿Y la identidad sexual? ¿Por qué la negra va detrás?

\section{Nuevos feminismos}

¿Y qué pregunto yo? ¿Cuál es la pregunta que yo puedo plantear? Yo no poseo nada, yo no soy un hombre. Jamaica Kincaid

Lo que mejor define a los nuevos feminismos, feminismos de la tercera ola, o incluso transfeminismos, es su cuestionamiento del propio feminismo. Esto quiere decir que, pese a la gran variedad de estrategias que han caracterizado a la teoría y prácticas feministas de las últimas tres décadas, existe una confluencia en torno al cuestionamiento del feminismo como movimiento de liberación de la "mujer". Desde el feminismo de mujeres de color, por ejemplo, se denuncia que no existe algo así como un "patriarcado universal" o una "lucha de la mujer" porque no existe una "mujer", sino "mujeres" en condiciones muy distintas. Desde los estudios y activismo queer, se denuncia que no hay ni tan siquiera "mujeres", sino cuerpos construidos como mujeres, de acuerdo con una división médica y jurídica meramente cultural. Así, aparecen las nociones 
de doble o triple opresión al hablar de la discriminación por raza o por orientación sexual, obviadas históricamente por el feminismo hegemónico. A esto se suma, en el caso de los cuerpos provenientes de diásporas, la discriminación bilateral por parte tanto de la comunidad de origen como de la comunidad de inserción. En Estados Unidos, por ejemplo, encontramos toda una serie de reivindicaciones de "mujeres" atrapadas en la jaula de lo que sus familias esperaban de ellas, esas “culturas que traicionan”, como dice Gloria Anzaldúa (2004) y lo que los hombres y mujeres de ese país esperaban de ellas (incluidas quienes querían "liberarlas"). Estas mujeres "en la encrucijada", "en la frontera" (Anzaldúa, 1981), necesitaron nuevas estrategias para autodefinirse y encaminar sus luchas. Al modo poscolonial, se vieron obligadas a crear un lenguaje nuevo que pudiera dar cuenta de la complejidad de sus identidades y, por tanto, de la complejidad de la opresión.

Los estudios interseccionales, como mostró Kimberlé W. Crenshaw (1991), nacieron para dar cuenta de esta encrucijada. Para definir la opresión es necesario trazar un mapa de las intersecciones que atraviesan a un mismo cuerpo. Todo es cuestión de determinar dónde este se sitúa, desde su ubicación geográfica a su relación con los otros cuerpos. Para entender cada situación personal hay que partir pues de un plano macro, entender el sentido de los mapas y la historia de los desplazamientos de los cuerpos. Después, hay que descender a un plano micro, atender a la ubicación de cada cuerpo en la sociedad, la comunidad, la familia y sus desplazamientos (desde los espacios públicos que habita hasta la manera de sentarse).

Lo que nos interesa en este punto es mostrar la conexión no solo del plano macro, sino del plano micro, con el marco colonial. Desde la propia historia de la filosofía occidental se ha definido al espíritu moderno-racional como espíritu colonial, esto es, como espíritu de controlar la naturaleza. Este espíritu es inherente a un dualismo metafísico, según el cual, el mundo está dividido en dos: res cogitans y res estensa, alma y cuerpo, naturaleza y hombre. En esta idea de naturaleza entran pues tanto los mares como los sentimientos (el dominio de las pasiones deviene obsesión teórica) y la razón ordenadora es la única que se escinde de la contingencia (cual Dios) ${ }^{10}$. Así, naturaleza es simplemente todo lo que no es el hombre. ¿Y qué no es el hombre? Las cosas, las bestias y las mujeres.

Desde este punto de vista, todo lo que no sea masculino, pero tampoco femenino, será bestial, desde los maricones hasta las focas. Mediante este binarismo, el hombre define la feminidad por oposición a su propia mitificación de

10 Ver Adorno y Horkheimer (2007), quienes sitúan los orígenes de este espíritu moderno de culto al logos (frente al mito) en el Odiseo homérico y su deseo de autoconservación. La luz de su hazaña sobria contrasta con la orgía imposible con que los mares le tientan. Pero esa luz, esa obsesión apropiadora (su palacio, su trono, su mujer), ilumina con una profunda violencia. Esa es la luz de la llustración. Solo así se puede entender cómo de la razón surgieron fenómenos tan genocidas como el imperialismo europeo o el holocausto nazi. 
la masculinidad. Y como la masculinidad no es sino una construcción, como la religión o la nación, la definición de lo que es el hombre cambiará de acuerdo con distintos intereses de poder ${ }^{11}$. Todo lo que no concuerde con dicha definición será defectuoso, tendrá una sexualidad desaforada (desde los negros a las ateas) o una virilidad dudosa (desde los asiáticos a los bisexuales), una mente subdesarrollada (desde las mujeres a los discapacitados) o pervertida (desde las bolleras hasta las "trans").

Así, en cada espacio y en cada tiempo habrá una separación entre lo que es un hombre y lo que no es un hombre, esto es, entre quienes poseen el mundo y quienes serán poseídas y poseídos. Frantz Fanon (1975) propuso una distinción entre la "zona del ser" y la "zona del no ser", basada en criterios raciales, para ilustrar este proceso. Dichos criterios, que pueden estar basados tanto en el color de la piel como en la cultura o la religión son, según Grosfoguel, los que constituyen "la línea divisoria transversal que atraviesa las relaciones de opresión de clase, sexualidad y género a escala global” (2011, p. 99). Se trata de un planteamiento que privilegia la raza sobre el resto de categorías y que resulta fundamental para toda teoría poscolonial, al tiempo que cuestionable.

El cuestionamiento que sugerimos es fundamental para nuestro propósito. No solo porque no es casualidad que el género sea relegado a un segundo plano (como tampoco lo es que la negra del poema poscolonial de Guillén vaya detrás). Si el discurso sobre el "ser" y el "no ser" lo fija quien tiene el poder, basta echar un vistazo a la historia de Occidente para observar la estructura patriarcal de las distintas sociedades. No fue el "ser humano" blanco quien trazó la línea del ser, ni quien colonizó América y el Caribe. Fue el "hombre blanco". Y fue "la otredad" de su "masculinidad blanca" la silenciada por las diversas instituciones, incluida la ciencia" ${ }^{12}$. Esto quiere decir que no se

11 Para profundizar en esta cuestión, ver Kimmel (2006). Según este autor, la historia de Estados Unidos es la historia whasp (white heterosexual anglosaxon protestant) y además el esfuerzo repetido por reconfirmar los límites de la masculinidad en la que este estrato social se define. Desde este punto de vista, la falta de humanidad de los esclavos o las mujeres nunca ha sido otra cosa que falta de "masculinidad", porque lo masculino ha sido el patrón de lo humano.

12 La homosexualidad, por ejemplo, es una otredad que ha tenido diversos estatus a lo largo del espacio y el tiempo. En Europa, con la modernización de las instituciones, su marginalización por parte de la moral religiosa, se debilita y es entonces cuando aparece la medicalización de la tendencia sexual. No es la Iglesia o el Gobierno, sino la Ciencia, quien prescribe su condición desviada, quien la patologiza. La clave es que la necesidad heterosexual de afirmar su nosotros explora nuevos campos para justificar la otredad, porque la "necesita". Y lo mismo ocurre con la raza. Si examinamos la historia, por ejemplo, de las Antillas inglesas, observamos que con la era victoriana, el prejuicio anti west-indian creció. ¿Por qué? Porque el siglo XIX convierte a la raza en una clave epistemológica para entender todo lo demás. En The West Indian and the Spanish Man (1860), Anthony Trollope describe a los criollos como una raza degenerada sin lengua, la raza de un broken english. El criollo, dice, "posee excepcional fuerza física, pero es ocioso... sensual, y se contenta con poco" (citado por James, Louis, 1999, p. 17, traducido por la autora). Esta descripción casi institucionalizada en el white world no tiene hoy el mismo peso que cualquiera de las recogidas en los diarios de los primeros colonizadores. Aquellos vivían atrapados en eras de tinieblas y construían mitos delirantes acerca de monstruos deformes. Ahora no es Dios, sino la ciencia, quien ayuda a definir la otredad, con las mismas pretensiones de universalidad. 
puede entender la raza sin la masculinidad, pero tampoco la masculinidad sin la raza. Todo retrato de poder quedaría incompleto sin este bifrontismo de las opresiones. Pero parece que esto es algo difícil de manejar. Le cuesta al marxismo quitarle protagonismo a la clase, le cuesta al poscolonialismo quitarle protagonismo a la raza.

La realidad es que es el feminismo negro el que se ha propuesto acabar con las jerarquías, con el protagonismo y entender toda opresión como una necesaria intersección de opresiones. La conexión del feminismo con el giro de tuerca poscolonial es máxima en este sentido, tanto que podríamos hablar de un feminismo poscolonial. Claro que este término es polémico en un doble sentido. Por una parte, hay cuerpos que no aceptan insertarse en el "feminismo" como artefacto ya en su origen colonial. Por otra, hay cuerpos que se sienten excluidos de lo poscolonial porque viven precisamente en la metrópoli, en el corazón del imperio (aunque ciertamente en la periferia). El término "decolonial" evitaría la confusión, aunque no el problema de que la noción de "mujer" o incluso de "género" que maneja el feminismo ya implica colonialidad. Tal y como sugiere María Lugones en su ineludible artículo: Género y colonialidad, "la organización social en términos de género no tiene por qué ser heterosexual o patriarcal" (Lugones, 2008, p. 4). Basta con echar un vistazo a lo largo del espacio y el tiempo para comprobarlo. Pero la palabra "género" ya presupone una organización determinada que impide una comprensión adecuada de la diversidad. En otras palabras:

No es necesario que las relaciones sociales estén organizadas en términos de género, ni siquiera las relaciones que se consideren sexuales... Tanto el dimorfismo biológico, el heterosexualismo, como el patriarcado son característicos de lo que llamo el lado claro/visible de la organización colonial/moderna del género. El dimorfismo biológico, la dicotomía hombre/mujer, el heterosexualismo, y el patriarcado están inscriptos con mayúsculas, y hegemónicamente en el significado mismo del género (Lugones, 2008, p. 4).

Esto refuerza la idea de que la interseccionalidad es necesaria, pero no por atender a la multiplicidad de opresiones que se cruzan (como variables aisladas que pasan a combinarse entre sí), sino por atender a la opresión en la necesaria interrelación de sus caras. Dotarla de un contenido previo, esto es, de unas categorías universales que en todo contexto estarán en cruce, sería un error. Quizá el concepto de clase social tenga sentido en el contexto europeo, pero para el indio tendría más sentido hablar de casta, o de ambas. Lo más importante es entender la opresión siempre como si de un prisma se tratase. Sin una de las caras el resto no puede consolidarse. Como afirma María Lugones:

Solo al percibir género y raza como entretramados o fusionados indisolublemente, podemos realmente ver a las mujeres de color. Esto implica que el término "mujer" en sí, sin especificación de la fusión no tiene sentido o tiene un sentido racista, ya que la lógica categorial históricamente ha seleccionado solamente el grupo dominante, las mujeres burguesas blancas heterosexuales y por lo tanto ha 
escondido la brutalización, el abuso, la deshumanización que la colonialidad del género implica (2008, p. 7).

Esto es algo por asumir para el pensamiento pos/decolonial. No se trata solo de que el patriarcado y el colonialismo sean indisociables, se trata de que nuestras categorías de análisis derivan de esa alianza y regulan nuestras posibilidades de discurso/acción. Como dice Nira Yuval-Davis, el patriarcado "todavía resulta un instrumento analítico muy grueso". Tan grueso que la propia autora no deja de ver a través del mismo, pues critica que "no permite ver el hecho de que en la mayoría de sociedades algunas mujeres tienen poder, al menos sobre algunos hombres, así como sobre algunas mujeres" (2011, p. 22). Aquí "algunos" y "algunas" puede sonar insuficiente si se tiene en cuenta que tres cuartas partes del mundo fueron penetradas y apropiadas, y que los hijos y en especial las hijas de esta violación aún hoy "valen menos que la bala que los mata" (Galeano, 2005, p. 59). Todas las mujeres blancas tienen que hacer acopio de su privilegio en este sentido.

Tampoco nos podemos contentar con la afirmación de que "en situaciones concretas, la opresión de las mujeres se cruza y articula con otras formas de opresión social y divisiones sociales" (Yuval Davis, 2011, p. 22). Una opresión se articula siempre con el resto, no en "situaciones concretas". Si se aísla, pierde significación. Así que el reto es asumir la complejidad, para lo que hacen falta instrumentos muy finos. Hay que buscarlos e intentar no perderse en el camino, pues se acabaría renunciando a toda generalización. Esta no renuncia a la teoría es el reto fundamental no solo del feminismo, sino de la teoría social hoy.

\section{Identidades diaspóricas II}

To survive in the Borderlands you must live sin fronteras be a crossroads Gloria Anzaldúa

"Nuestro tiempo" (occidental) es el de la lucha por el reconocimiento de las "identidades". Los grupos minoritarios o simplemente subalternos (mujeres, no blancos, etcétera) están cambiado el mundo. Cuando la cuestión de la redistribución parecía ser el motor de todas las protestas y las utopías, resultó que la opresión no era un concepto tan simple, no se podía reducir unívocamente. Apareció la palabra identidad en el mapa de la discusión y la igualdad de las democracias de occidente fue denunciada como ciega. Porque, como todo el mundo sabía, no éramos iguales. Éramos distintos y distintas, y en nuestro sistema la diferencia se pagaba cara.

Las teorías postcoloniales se basan en esta asunción. La opresión colonial no es solo una cuestión de dominio económico, sino cultural, que se despliega en procesos de asimilación diversos, incluidas las prácticas genocidas. Fanon postuló que las mentes están también colonizadas y que los cuerpos antillanos 
o africanos tenían piel negra, pero máscaras blancas (1975). Estas máscaras les hacían verse a sí mismos a través de los ojos del colonizador. Por esto, una de las tareas postcoloniales más importantes era la exploración del hecho de que la identidad es inseparable de la citada "colonialidad del poder".

Fanon emigró a Europa para estudiar esta conexión y, como otros autores antillanos, llevó a cabo un examen crítico acerca de las verdades "occidentales". Su desplazamiento, físico y teórico, permitió esta suerte de deconstrucción. En realidad, todas las deconstrucciones tienen que ver con algún tipo de desplazamiento, en el que un binarismo supuestamente natural, con su jerarquía inherente, se revela como meramente cultural y, por tanto, como reversible. Pero no se trata solo de un desplazamiento "mental". Mi tesis es que los primeros momentos históricos de deconstrucción del colonialismo fueron desarrollados por personas de todo el mundo unidas por un hecho fundamental: formar parte de la Diáspora global desde las colonias a los viejos y nuevos imperios. Estas personas estaban literalmente desplazadas.

Así pues, al mismo tiempo que se alzaban las voces en las colonias (independizadas o no), en el nuevo imperio algunos grupos empezaron a luchar por sus derechos civiles. Venían también de diásporas explícitamente forzosas, como la africana, o implícitamente forzosas, como la antillana o la chicana, resultado de la ocupación estadounidense de Puerto Rico, República Dominicana o el norte de México. Estos grupos denunciaban que hubiera una identidad hegemónica que disfrutaba de los privilegios democráticos y del bienestar, o al menos podía optar a ellos por medio de la lucha, como en el caso de los hombres blancos trabajadores. Las identidades subalternas, sin embargo, ni disfrutaban de los mismos privilegios (aunque oficialmente gozaran del título de ciudadanía e incluso pudieran votar o vivir desahogadamente) ni sus reclamas estaban incluidas en las luchas.

El feminismo en Occidente en general y la lucha negra en Estados Unidos, en particular, son dos paradigmas de la reacción contra esta situación. Como movimientos por los derechos civiles reivindicaron la identidad "mujer" y la identidad "negro" como identidades inferiorizadas por la cultura hegemónica, y exigieron reconocimiento para disfrutar de esa ciudadanía plena que las constituciones y las declaraciones de independencia prometían. Dentro de ellos, y de muchos otros, nuevos grupos reivindicaron sus identidades subsubalternas, como las "lesbianas" dentro de las "mujeres" y las "negras" dentro de los "negros". Y denunciaron su invisibilidad.

Estas reivindicaciones sociales que, en su mayoría, tienen origen en cuerpos desplazados, supusieron un giro de tuerca a niveles epistemológicos. Mostraron el sesgo colonial/eurocéntrico de lo que se entendía por conocimiento objetivo (filosófico y científico). En consecuencia, implicaron una complejización vertiginosa de la teoría social, abriendo un espacio inusitado a "lo personal" en 
el estudio, al discurso no solo de quien era sujeto, sino "objeto" de estudio, o incluso a la palabra de quien ni siquiera era objeto de estudio.

Sin embargo, estamos lejos de percibir la incidencia de estos cuestionamientos en la práctica académica. Su alcance epistemológico es tan profundo que no podemos siquiera determinar qué sería de la ciencia aplicada a la descolonización del conocimiento. Este alcance de la transformación en el conocimiento, que ocasionaría una pérdida brutal de privilegios para muchos sectores, produce miedo y rechazo. Los cuestionamientos decoloniales implicarían un cuestionamiento del régimen económico, algo que dificulta enormemente su difusión y aplicación. Como explica Aníbal Quijano:

No existe una 'pre' o un 'pos' de la jerarquía racial/étnica a escala mundial en relación con el proceso de acumulación capitalista. Desde la formación inicial del sistema-mundo capitalista, la incesante acumulación de capital se mezcló de manera compleja con los discursos racistas, homofóbicos y sexistas del patriarcado europeo (2007, p. 19).

El decolonialismo es pues un proyecto inevitablemente político donde se cuestiona el régimen socioeconómico y cultural vigente. Se puede hablar de un régimen general en la medida en que el espacio global se reconoce como espacio neoliberal y como, lo que Avtar Brah ha denominado, un "espacio de la diáspora". Un espacio donde cada cuerpo se sitúa literal o metafóricamente en la frontera, donde se cruzan diversos ejes de opresión y "donde la diferencia y lo común figuran en una relacionalidad no reductiva". En dicho marco "los ejes de diferenciación y división tales como la clase, el género y la sexualidad articulan múltiples prácticas económicas, políticas y culturales a través de las cuales se ejerce el poder" (Brah, 2011, p. 281).

Creo que es importante no caer pues en un reduccionismo identitario "etnosexualizado", por llamarlo de algún modo, donde se olvide la impronta cultural de la dinámica económica en la identidad. Quiero decir con esto que "mujeres" de clases "medias-cultas" de diferentes puntos del mundo, y diferentes "razas" y sexualidades, quizá tengan más en común entre ellas en muchos planos que con respecto a sus compatriotas de clases "populares". Hay que tener esto en cuenta especialmente para el ámbito poscolonial académico, no solo por su incidencia en el elemento racial, sino en el sentido de que quién hace "teoría" probablemente tenga una posicionalidad diaspórica más "privilegiada".

En este punto resulta fundamental atender a la pregunta que planteara la autora estadounidense/bengalí Gayatri Spivak (2006): “ipuede el (sujeto) subalterno hablar?". En realidad, todo planteamiento postcolonial tiene que partir de esta interrogante para elaborar cualquier tentativa. Dentro de la subalternidad, habrá quienes emigren y puedan escribir libros y quienes emigren y puedan escribir la lista de la compra y quiénes no puedan hacer ni lo uno ni lo otro. Aparte de esto, está la tarea de desprenderse del pensamiento colonial, 110 inscrito en las palabras y el propio cuerpo. 
Por otra parte, si lo que no se nombra no existe, también es cierto que lo que se nombra pierde su idiosincrasia, su diversidad, su condición trans (transgénero, tránsfuga, transitoria). Teniendo en cuenta la diversidad actual de identidades en lucha por su reconocimiento, vivimos siempre en el riesgo de que el sujeto subalterno devenga verdugo (y entonces hable por los codos) o sea aniquilado por la identidad subalterna asignada (y entonces enmudezca irremediablemente). Entonces, ¿desde qué identidad puede la persona subalterna erigir su espacio de discurso/lucha?

Vivimos en un espacio de la diáspora donde la contradicciones culturales se multiplican. Ese espacio de la transmodernidad, como dice Enrique Dussel, es el momento de una alternativa posible. Una alternativa que emerge de los márgenes y que no está dentro ni fuera de la modernidad, sino en la frontera. Claro que, como dice Avtar Brah, "la posicionalidad diaspórica o de frontera no asegura por sí misma un punto de vista privilegiado ni una comprensión de las relaciones de poder", pero sí "crea un espacio en el cual las mediaciones experimentadas pueden entrecruzarse de forma que hagan más accesible dicha comprensión" (2011, p. 240). En el espacio diaspórico las tierras de origen y emigración son puertas abiertas y jaulas al mismo tiempo, y quienes solo ven una parte están tragándose una mentira, un binarismo estrecho.

¿Dónde está la habitación propia (o la casa, o el patio, por no proponer algo tan burgués y tan inglés) de esos cuerpos en desplazamiento, de esas identidades en rebelión que definen al feminismo hoy? En un discurso propio que no ha de ser monócromo, pues todo intento de univocidad llevará a la patología. Como dice la poetisa chicana Berenice Zamora, mezclando intencionadamente las lenguas que la configuran, "You insult me/ When you say I'm/ Schizophrenic/ My divisiones are/ Infinite" (1976, p. 73). La identidad no es una categoría trascendental, sino una cuerda floja en la que hacer equilibrios. La cuestión no es encontrar la esencia, sino crear identidades y coaliciones que puedan satisfacer los intereses personales. Como dice la filósofa estadounidense Judith Butler, la realidad es performance y, por tanto, ilimitada "posibilidad performativa":

El hecho de que la realidad de género se cree mediante actuaciones sociales continuas significa que los conceptos de un sexo esencial y una masculinidad o femineidad verdadera o constante también se constituyen como parte de la estrategia que oculta el carácter performativo del género y las posibilidades performativas de que proliferen las configuraciones de género fuera de los marcos restrictivos de dominación masculinista y heterosexualidad obligatoria (2001, p. 72).

\section{Conclusión}

Hasta ahora se ha intentado mostrar la amplitud del vínculo (histórico, conceptual y político) entre las propuestas decoloniales y los nuevos feminismos. El recorrido realizado muestra, asimismo, cómo diferentes identidades 
subalternas llegan a hablar y a reconocerse como "diaspóricas" o fronterizas (como construidas e híbridas, pero también como propias e inexpugnables). Tras dicho recorrido el feminismo se vuelve necesariamente transfeminismo, no solo porque cuestiona toda naturalización en torno al género sino toda naturalización. Se desprende de sus propios orígenes poniendo en evidencia no solo los presupuestos teóricos asumidos, sino los modos de obtener conocimiento heredados. Se descoloniza y esto resulta tremendamente revolucionario a la par que peligroso. Ya no se sabe cuál es el acervo común de lo humano más allá del perfomance de la historia. El discurso de los derechos universales se derrumba como torre gemela.

Pero este es un reto que hay que asumir. Mucha gente piensa que la exportación del humanismo es la parte buena de la empresa colonial. Al mismo tiempo, casi nadie piensa que el cuestionamiento del humanismo es la empresa fundamental del poscolonialismo. Porque oficialmente no lo es. Oficialmente el reconocimiento de las literaturas no metropolitanas, el multiculturalismo teórico y constucional en Canadá o la lucha racial en Estados Unidos son avances del humanismo recogidos en los departamentos de las universidades del viejo continente (Europa) y el nuevo imperio (Estados Unidos). Pero si cavamos bien profundo nos encontramos con que la decolonialidad no se reduce a la tarea de luchar por el reconocimiento de las categorías subalternas. Va más allá, va al encuentro de las paradojas sangrantes de todas las teorías que empiezan con "pos". Lo poscolonial es posestructural: cuestiona ya la lista de categorías, deconstruye el edificio colonial desde los cimientos. Y es al tiempo edificación, proliferación de identidades transcategoriales, creación semiótica de un universo poshumanista.

El caso es que la transformación ya está en marcha. Los cuerpos están en desplazamiento permanente, cruzando todo tipo de fronteras y, algunos de ellos, están hablando. Se puede decir que la descolonización es un proyecto político en auge, y no en declive, tras las independencias. Hoy nos encontramos descripciones del cuerpo femenino como territorio de conquista del hombre blanco usadas tanto por indígenas americanas como por mujeres musulmanas. Esto plantea un duro reto de coaliciones, pues varían los cuerpos y los intereses de las reivindicaciones. Pero da cuenta de un acervo común en la oposición a la colonialidad del poder.

Obviamente, y a pesar de tratarse de un proyecto en auge, la teoría y la práctica decoloniales tienen que enfrentarse al monstruo consagrado del eurocentrismo, verdadero fantasma que recorre el mundo desde hace unos siglos. Estamos aún en la orilla de lo que será un universo transmoderno. Para el caso del feminismo, el reto es enorme, pues habrá quien aproveche la transición para relativizar el peso de la opresión sexual. Pero no podemos quedarnos en la orilla por miedo a perder los siglos de empoderamiento ilustrado. Hay que nadar mar adentro. El feminismo será poscolonial o no será. 


\section{Referencias}

Adorno, Theodoro \& Horkheimer, M. (2007). Dialéctica de la Ilustración. Fragmentos filosóficos. Madrid: Akal.

Anzaldúa, Gloria. (2004). Los movimientos de rebeldía y las culturas que traicionan. En Traficantes de sueños (comps.), Otras inapropiables. Madrid: Traficantes de Sueños.

Anzaldúa, Gloria. (1987). Borderlands, the New Mestiza. San Francisco: Aunt Lute Books.

Benjamin, Walter. (1991). Sobre el lenguaje en general y sobre el lenguaje de los humanos. En Para una crítica de la violencia y otros ensayos. Madrid: Taurus.

Butler, Judith. (2001). El género en disputa. Barcelona: Paidós

Brah, Avtar. (2011). Cartografías de la diáspora. Identidades en cuestión. Madrid: Traficantes de Sueños.

Bruneau, Michel. (2010). Diasporas, trasnational spaces and comunities. En Reiner Bauböck y Thomas Faist (eds.), Diaspora and Trasnationalism. Concepts, Theories and Methods. Holanda: Amsterdam University Press.

Castro Gómez, Santiago y Grosfoguel, Ramón (eds.). (2007). El giro decolonial. Reflexiones para una diversidad epistémica más allá del capitalismo global. Bogotá: Siglo del Hombre Editores.

Cesaire, Aimé. (1983). Cahier du retour au pays natal. Paris: Editions Présence Africaine.

Crenshaw, Kimberlee. (1991). Mapping the Margins: Intersectionality, Identity, Politics, and Violence Against Women of Colour. Stanford Law Review, 43(6), 1241-1299.

Dussel, Enrique. (2005). Transmodernidad e interculturalidad. Interpretación desde la Filosofía de la Liberación. Mexico, D.F.: Universidad Autónoma Metropolitana-Unidad de Iztalapa.

Fanon, Frantz. (1975). Peau Noire, Masques Noires. Paris: Les Éditions du Seuil.

Grosfoguel, Ramón. (2011). La descolonización del conocimiento. Diálogo crítico entre la visión descolonial de Frantz Fanon y la sociología descolonial de Boaventura de Sousa Santos. En Formas Otras: saber, nombrar, narrar, hacer. Edición de las actas del IV Training Seminar del Foro de Jóvenes Investigadores en Dinámicas Interculturales (FJIDI). Centro de Estudios y Documentación Internacionales de Barcelona (CIDOB). 
Galeano, Eduardo. (2005). El libro de los abrazos. Madrid: Siglo Veintiuno de España.

Glissant, Edouard. (1981). Le discours antillais. Paris: Editions du Seuil.

Guillén, Nicolás. (2003). El son entero. Biblioteca Virtual Universal. Recuperado de http://www.biblioteca.org.ar/libros/88723.pdf

Hofmannsthal, Hugo. (1990). La carta de Lord Chandos. En Jaime García Terrés (ed. y trad.), La carta de Lord Chandos y algunos poemas. México: Fondo de Cultura Económica.

Innes, Lynette. (2007). The Cambridge Introduction to Postcolonial Literatures in English. Reino Unido: Cambridge University Press.

James, Louis. (1999). Caribbean Literature in English. London: Longman Pub Group.

Kincaid, Jamaica. (2007). Autobiografía de mi madre (Alejandro Pérez Viza, trad.). Nafarroa: Txalaparta.

Kimmel, Michael. (2006). Manhood in America: A cultural history. New York: Oxford University Press.

Lugones, María. (Julio-Diciembre, 2008). Colonialidad y género. Tabula Rasa, (9).

Lugones, María. (2005). Multiculturalismo radical y feminismos de mujeres de color. Revista Internacional de Filosofía Política, (25), 61-76.

Mignolo, Walter. (2007). El pensamiento decolonial: Desprendimiento y apertura. Un manifiesto. En Santiago Castro Gómez y Ramón Grosfoguel (eds.), El giro decolonial. Reflexiones para una diversidad epistémica más allá del capitalismo global. Bogotá: Siglo del Hombre Editores.

Pérez Flores, Larisa. (2014). Jamaica Kincaid y la diáspora antillana: mujeres, islas y jaulas. Relaciones Internacionales, (25), 103-121.

Portes, Alejandro. (1997). Globalization from Below: The Rise of Transnational Communities. Estados Unidos: Princeton University.

Morrison, Tony. (1993). La isla de los caballeros (Mireia Bofill trad.). Barcelona: Ediciones B.

Quijano, Aníbal. (2007). Colonialidad del poder y clasificación social. En Santiago Castro Gómez y Ramón Grosfoguel (eds.), El giro decolonial. Reflexiones para una diversidad epistémica más allá del capitalismo global. Bogotá: Siglo del Hombre Editores. 
Spivak, Gayatri. (2006). Can the subaltern speak. En Bill Ashcroft, Gareth Griffiths y Helen Tiffin (eds.), The Postcolonial Studies Reader. New York/London: Taylor and Francis Group. 